\title{
Risk Factors, Antimicrobial Susceptibility Patterns and Carbapenem Resistance Mechanisms of Elizabethkingia anophelis Clinical Isolates From a University Tertiary Hospital in Southwest China
}

\author{
Yanbin Chang \\ Chongqing Medical University First Affiliated Hospital \\ Daiqin Zhang \\ Chongqing Medical University First Affiliated Hospital \\ Siqiang Niu \\ Chongqing Medical University First Affiliated Hospital \\ Qian Chen \\ Chongqing Medical University First Affiliated Hospital \\ Qiuxia Lin \\ Chongqing Medical University First Affiliated Hospital \\ Xiaobing Zhang ( $\sim$ xhpg85@aliyun.com ) \\ Chongqing Medical University First Affiliated Hospital https://orcid.org/0000-0002-1171-0740
}

\section{Research}

Keywords: Elizabethkingia anophelis, risk factors, antimicrobial susceptibility patterns, carbapenem resistance

Posted Date: August 7th, 2020

DOI: https://doi.org/10.21203/rs.3.rs-53369/v1

License: (c) (i) This work is licensed under a Creative Commons Attribution 4.0 International License. Read Full License 


\section{Abstract}

Purpose: Elizabethkingia anophelis (E. anophelis) is an important extensively drug-resistant (XDR) pathogen to which there are limited therapeutic options. E. anophelis is perpetually misidentified as Elizabethkingia meningoseptica (E. meningoseptica) by conventional methods. Consequently, this study reassessed risk factors for infection and mortality, antimicrobial susceptibility patterns and carbapenem resistance mechanisms of E. anophelis.

Methods: This retrospective case-control study was conducted to reveal the risk factors associated with $E$. anophelis infection and in-hospital mortality from 2015-2019 in a university tertiary hospital in southwest China using univariable and multivariable logistic-regression analysis. Case patients infected with $E$. anophelis isolates and controls patients with non- $E$. anophelis infections were compared at a ratio of 1:3 during the same time period. We employed the broth microdilution method to investigate the antimicrobial susceptibility profiles of $39 \mathrm{E}$. anophelis strains. PCR amplification, DNA sequencing and gene cloning were used to investigate the mechanisms of carbapenem resistance in $E$. anophelis.

Results: We collected 39 non-repetitive E. anophelis isolates over the study period. Multivariate analysis indicated that coronary artery disease, chronic obstructive pulmonary disease, surgery in the past 6 months, anemia and systemic steroid use were independent risk factors for the acquisition of $E$. anophelis. Additionally, anemia was the only independent risk factor associated with in-hospital mortality in patients with $E$. anophelis infections. E. anophelis isolates showed high in-vitro susceptibility towards minocycline (100\%) and piperacillin/tazobactam (71.8\%), but were resistant to colistin, fosfomycin, ceftazidime/avibactam and aztreonam/avibactam. Additionally, we show that two metallo- $\beta$-lactamases (MBLs) BlaB and $\mathrm{GOB}$, are responsible for carbapenem resistance and the serine-- $\beta$-lactamase, $\mathrm{CME}$, is functionally involved in resistance to cephalosporins and monobactams. Importantly, the various putative efflux pumps in E. anophelis are not responsible for resistance.

Conclusion: Our findings will help clinicians identify high-risk patients and suggest that minocycline should be considered as an antibiotic therapeutic option for infections caused by $E$. anophelis. Additionally, carbapenem resistance in $E$. anophelis isolates is mainly associated with the MBLs, BlaB and GOB.

\section{Introduction}

Elizabethkingia anophelis (E. anophelis) is an aerobic, immotile, oxidase-positive, indole-positive, Gram-negative, nonfermenting bacillus belonging to the genus Elizabethkingia and the family Flavobacteriaceae which was first isolated from midgut of the mosquito Anopheles gambiae in 2011 [1]. The first clinically significant $E$. anophelis infection was associated with a case of neonatal meningitis in Bangui, Central African Republic in 2011 [2]. Thereafter, the prevalence of E. anophelis infections has been rampant; it is the primary species of Elizabethkingia genus infections that have recently occurred in Singapore [3], Hong Kong [4], the United States [5, 6, 7, 8], South Korea [9] and Taiwan [10]. E. anophelis is an important opportunistic pathogen associated with various invasive infections in adults with underlying diseases and infants (premature and neonates) $[11,12]$. Several outbreaks have occurred in Singapore and in the Midwestern United States of Wisconsin, Illinois, and Michigan, where the fatality rate of patients with $E$. anophelis infections ranged from $30-60 \%[5,6,7,8]$. A recent study indicated that $E$. anophelis has been perpetually misidentified as Elizabethkingia meningoseptica (E. meningoseptica) using conventional methods (API/ID32, Phoenix 100 ID/AST, Vitek 2 and Vitek MS) [13]. Therefore, most of the previously reported data regarding the clinical characteristics, antimicrobial susceptibility patterns and antimicrobial resistance mechanisms of $E$. anophelis could be incorrect.

Extensive research has shown that $E$. anophelis isolates are resistant to most $\beta$-lactams, carbapenems and aminoglycosides [4, $5,14,15,16,17]$. Extensively drug-resistant pathogens pose a therapeutic dilemma for clinicians and are therefore associated with a high mortality rate and poor prognosis. Interestingly, different testing methods and geographic variation lead to obvious differences in patterns of susceptibility. So far however, the susceptibility patterns of $E$. anophelis isolates have not been reported in China, especial with data collated using the more robust broth dilution method. Genome-wide analysis reveals that this multidrug-resistant pathogen carries a class A serine- $\beta$-lactamase, CME, 2 metallo- $\beta$-lactamases, GOB and BlaB, in addition

Page 2/16 
to numerous putative efflux pump genes $[5,18,19,20]$. However, no studies have focused on the functions of these $\beta$ lactamases and putative efflux pumps in E. anophelis isolates. In addition, data reporting on the risk factors for infection and mortality of patients with an E. anophelis infection may potentially help clinicians identify high risk patients and inform on future therapeutic strategy.

The present study was initiated to: (i) identify the risk factors associated with $E$. anophelis infection and in-hospital mortality, (ii) investigate the antimicrobial susceptibility patterns and carbapenem resistance mechanisms of $E$. anophelis isolates and

(iii) characterize the functions of $\beta$-lactamases and putative efflux pumps expressed in $E$. anophelis isolates.

\section{Methods}

\section{Bacterial Strains}

This study used the database of clinical isolates provided by the clinical laboratory of a 3200-bed university-affiliated medical center (Chongqing, China) to collect the strains that were identified as Elizabethkingia species between January 2015 and December 2019. Microbial identification was performed in the microbiology laboratory using the VITEK2 compact (bioMérieux, Inc., NC, USA) system and the VITEK MS (bioMérieux, MO, USA) system. All Elizabethkingia species strains were stored at $80^{\circ} \mathrm{C}$ in $15 \%$ glycerol until use. Complete $16 \mathrm{~S}$ rRNA gene sequencing was used to reconfirm the identity of all isolates. The primers used for amplification and sequencing of the 16S rRNA gene are listed in Additional file 1. The sequences were assembled using Seqman (DNAStar) and compared with publicly available sequences in the NCBI

(http://www.ncbi.nlm.nih.gov) using the BLAST algorithm. Strains were considered to be accurately identified when a strain shared $>99.0 \% 16$ S rRNA sequence with a type of strain in GenBank.

\section{Data collection and Clinical Definitions}

The electronic medical records of the patients were collected retrospectively. We excluded subjects with the following characteristics: patients with polymicrobial infection and patients admitted for $<48$ hours. Only the first episode was taken into account for patients with more than one positive E. anophelis culture. To evaluate the risk factors of E. anophelis infection, controls were defined as randomly selected patients with non- $E$. anophelis infections during the same time period (at a 3:1 ratio to the case group). Selected epidemiological, demographic, clinical, laboratory, treatment and outcome data were obtained from the electronic medical records. Empirically administering agents to isolates which were not susceptible was defined as inappropriate empirical antimicrobial therapy. Shock was defined as the coexistence of systolic pressure of $<90 \mathrm{~mm} \mathrm{Hg}$ and organ dysfunction of the respiratory system, liver or kidneys. Serum total protein content of $<60 \mathrm{~g} / \mathrm{L}$ or albumin content $<$ $25 \mathrm{~g} / \mathrm{L}$ were the criteria used to define hypoproteinemia. Hypokalemia was diagnosed at a serum potassium level $<3.5 \mathrm{mmol} / \mathrm{L}$. Systemic steroid use was defined as oral or intravenous administration of at least $20 \mathrm{mg} /$ day of a steroid (prednisone, hydrocortisone, methylprednisolone or dexamethasone) within 1 month of infection. We defined anemia as hemoglobin < $130 \mathrm{~g} / \mathrm{L}$ in men and $<120 \mathrm{~g} / \mathrm{L}$ in women according to the WHO (World Health Organization) guidelines. The primary clinical outcome was in-hospital mortality.

\section{Antimicrobial Susceptibility Testing}

The reference broth microdilution method was used to evaluate the minimum inhibitory concentrations (MICs) of all antibiotics in E. anophelis and recombinant strains according to the Clinical and Laboratory Standards Institute (CLSI) M07-Ed11 (2019). The criterion suggested by the CLSI for "other non-Enterobacteriaceae" was used to determine the susceptibility of isolates to antibiotics with the exception of ceftazidime/avibactam, aztreonam/avibactam, vancomycin, tigecycline, rifampicin, colistin and fosfomycin. The US Food and Drug Administration (FDA) Enterobacteriaceae criteria was used to interpret isolate susceptibility to tigecycline (resistant MIC $\geq 8 \mu \mathrm{g} / \mathrm{mL}$, susceptible MIC $\leq 2 \mu \mathrm{g} / \mathrm{mL}$ and intermediate $\mathrm{MIC}=4 \mu \mathrm{g} / \mathrm{mL}$ ). The MIC breakpoint applied to vancomycin and rifampicin was adapted from the CLSI criteria for Staphylococcus spp.. A MIC of $\geq$ $16 / 4 \mu \mathrm{g} / \mathrm{mL}$ was considered resistant for the combination ceftazidime/avibactam and aztreonam/avibactam. Colistin MICs were interpreted at susceptible breakpoints of $\leq 2 \mu \mathrm{g} / \mathrm{mL}$ and resistant breakpoints of $>2 \mu \mathrm{g} / \mathrm{mL}$ according to the European Committee on Antimicrobial Susceptibility Testing (EUCAST) Enterobacteriaceae criteria. Likewise, for fosfomycin, we elected 
to use the susceptible breakpoint of $\leq 32 \mu \mathrm{g} / \mathrm{mL}$ and resistant breakpoint of $>32 \mu \mathrm{g} / \mathrm{mL}$ based on EUCAST Enterobacteriaceae criteria. The reference strains Escherichia coli (ATCC 25922) and Pseudomonas aeruginosa (ATCC 27853) were used as negative controls and quality controls for antibiotic susceptibility testing.

\section{The Confirmation and Cloning of Drug Resistance Genes}

The presence of carbapenemase genes (blaKPC, blaIMP, blaVIM, blaNDM, blaBlaB, blaGOB and blaOXA-48-like) and extendedspectrum betalactamase (ESBL) genes (blaTEM, blaSHV, blaCME and blaCTX-M) were confirmed by conventional polymerase chain reaction (PCR) assays and sequencing.

We amplified the full length coding sequences (CDSs) of genes using specific primers flanked by restriction sites (EcoRl, Xhol or BamHI). These included genes encoding: blaCME, blaBlaB, blaGOB, CzcABC family efflux RND transporter, Efflux ABC transporter (ATP-binding protein), MATE family of MDR efflux pump, small multidrug resistance family (SMR) protein and MFStype transporter. Amplified PCR fragments were purified and cloned into the corresponding sites of the pET-28a plasmid and were electroporated into BL21 competent $E$. coli. Successful cloning was verified by PCR and sequencing analysis. The sets of primers used for amplification and sequencing of target genes are provided in Additional file 1.

\section{Statistical Analysis}

The data were evaluated using SPSS statistical software (version 22.0, IBM). Data are presented as counts (proportions) for categorical variables. Direct comparisons between two groups were analyzed by the $\chi 2$ test or Fisher's exact test. Mean ( \pm standard deviation) was used to express normally distributed continuous variables and median ( \pm inter-quartile range) was calculated for non-normally distributed variables. Comparisons between two groups were conducted using a Student's t-test for normally distributed variables or a Mann-Whitney $U$ test for non-normally distributed variables. To evaluate independent risk factors for the infection and in-hospital mortality of $E$. anophelis isolates we examined all plausible variables using a univariate analysis. Risk factors with a $\mathrm{P}$ value $<0.1$ as detected by the univariate analysis were included in a multivariate logistic regression model with the enter method. Odds ratios (ORs) and 95\% confidence intervals (Cls) were determined for each risk factor of infection and in-hospital mortality. A two-tailed $P$ value $<0.05(P<0.05)$ was considered statistically significant.

\section{Results}

\section{Clinical Characteristics}

A total of 59 non duplicated Elizabethkingia isolates were collected from the clinical microbiology laboratory to investigate microbial traits. Full 16S rRNA gene sequencing was performed on 59 Elizabethkingia clinical strains. After comparison to the available sequences in the NCBI using BLAST, 16S rRNA sequencing showed that 39 isolates were identified as Elizabethkingia anophelis R26.

Of the E. anophelis isolates with a documented site of infection, 19 (48.7\%) were from the respiratory tract, 8 (20.5\%) were from the urinary tract, 6 (15.3\%) were from blood, 3 (7.6\%) were from cerebrospinal fluid, 2 (5.1\%) were from the tip of the venous catheter and 1 (2.6\%) was from peritoneal fluid (Table 4). From January 2015 to December 2019, 39 E. anophelis samples were isolated from 39 consecutive patients which were enrolled in the study. These patients consisted of 21 males (53.8\%) and 18 females (46.2\%) with a median age of 61.

Notably, chronic obstructive pulmonary disease was the most frequent comorbidity (76.9\%), followed by anemia (66.7\%). The empirical antibiotics used in the 39 patients included: carbapenems (38.5\%), $\beta$-lactam/lactamase inhibitors (33.3\%), $\beta$-lactams (30.8\%), teicoplanin (25.6\%), levofloxacin (17.9\%), aminoglycosides (17.9\%), minocycline $(12.8 \%)$ and antibiotics administered either alone or in combination (Table 4), $84.6 \%$ of these empirical antibiotic therapies were deemed as inappropriate empirical antibiotic use. Overall in-hospital mortality rate of patients with $E$. anophelis infection was $51.3 \%$. $\beta$-lactam/lactamase inhibitor antibiotics were used significantly more in patients which did not survive $(P=0.041)$. 


\section{Risk Factors and Clinical Outcomes of E.anophelisinfections}

The potential risk factors for the acquisition of E. anophelis infections are shown in Table 1. The univariate analysis indicated that hypertension, cerebrovascular diseases, chronic obstructive pulmonary disease, renal diseases, surgery in the past 6 months, anemia, hypoproteinemia and hypokalemia were significantly more frequent in patients with $E$. anophelis infections ( $P$ $<0.05)$. Elderly patients are more likely to present with an $E$. anophelis infection $(P<0.05)$. In the multivariate analysis, coronary artery diseases (OR 3.98, 95\% Cl: 1.56-10.17, $\mathrm{P}=0.004)$, chronic obstructive pulmonary disease (OR 6.71, 95\% Cl: 1.55-28.99, $\mathrm{P}=0.011)$, surgery in the past 6 months (OR 18.04, 95\% Cl: $3.29-98.87, \mathrm{P}=0.001)$, anemia (OR 6.72, 95\% Cl: $1.12-40.42, \mathrm{P}=$ $0.038)$ and systemic steroid use (OR $9.87,95 \% \mathrm{Cl}$ : $1.30-74.94, \mathrm{P}=0.027)$ were independent risk factors for the acquisition of an E. anophelis infection.

Univariate and multivariate logistic regression analysis results for the factors assosiated with in-hospital mortality are shown in Table 2. Univariate analysis showed that cerebrovascular disease $(P=0.035)$, chronic obstructive pulmonary disease $(P=$ 0.020), nasogastric tube insertion $(P=0.008)$ and anemia $(P=0.002)$ were associated with a higher mortality rate. Using further multivariate analysis, anemia (OR $86.38,95 \% \mathrm{Cl}: 1.42-5251.29 ; \mathrm{P}=0.033)$ was identified to be the only independent risk factor for in-hospital mortality in patients with $E$. anophelis infections.

\section{Antimicrobial Susceptibility}

The susceptibility of the $39 \mathrm{E}$. anophelis isolates to the antimicrobial agents tested in the study are shown in Table 3. The isolates showed high in-vitro susceptibility towards minocycline (100\%), piperacillin/tazobactam (71.8\%) and lower in-vitro susceptibility towards levofloxacin (38.5\%), ciprofloxacin (30.8\%), rifampicin (20.5\%), piperacillin (17.9\%) and tigecycline (10.3\%). The $\mathrm{MIC}_{50}, \mathrm{MIC}_{90}$ and $\mathrm{MIC}$ range of minocycline in the isolates was $0.5,1$, and $0.25-1 \mu \mathrm{g} / \mathrm{mL}$, respectively. Whereas the $\mathrm{MIC}_{50}, \mathrm{MIC}_{90}$ and MIC range of piperacillin/tazobactam was 16,32 , and $4-64 \mu \mathrm{g} / \mathrm{mL}$, respectively. All of the isolates displayed resistance to vancomycin, ceftazidime, cefepime, aztreonam, ceftazidime/clavulanic acid, cefepime/clavulanic acid, colistin and fosfomycin according to the breakpoints used. Note that while all isolates produced MBLs BlaB and GOB, aztreonam/avibactam could not further inhibit growth.

\section{Identifcation of $\beta$-lactamases present in Elizabethkingia anophelis Isolates}

PCR experiments were used to detect the presence of $37 \mathrm{blaGOB}, 37 \mathrm{blaBlaB}$ and $36 \mathrm{blaCME} \beta$-lactamase genes in $39 \mathrm{E}$. anophelis isolates (Table 4). Sequence alignments showed that $E$. anophelis strains harbored 2 types of the blaCME gene, blaCME-1 ( $\mathrm{n}=34)$ and blaCME-2 $(\mathrm{n}=2), 8$ types of the blaBlaB gene, including blaBlaB-29 (17), blaBlaB-2 (7), blaBlaB-1 (5), blaBlaB-17 (3), blaBlaB-3 (1), blaBlaB-9 (1), blaBlaB-33 (1) and blaBlaB-34 (1), and 8 types of the blaGOB gene, including blaGOB-38 (19), blaGOB-20 (8), blaGOB-32 (3), blaGOB-50 (3), blaGOB-39 (1), blaGOB-4 (1), blaGOB-40 (1) and blaGOB-45 (1). The most commonly detected combination of $\beta$-lactamases was $C M E-1+B l a B-29+G O B-38(\mathrm{n}=17)$.

We also investigated the presence of other $\beta$-lactamase genes. None of the $39 \mathrm{E}$. anophelis isolates harbored carbapenemase genes (blaKPC, blaIMP, blaVIM, blaNDM and blaOXA-48-like) or ESBLs genes (blaTEM, blaSHV and blaCTX-M).

\section{MICs of Recombinant Strains}

To further evaluate the function of $\beta$-lactamases, the most prevalent versions of blaCME, blaBlaB and blaGOB genes from $E$. anophelis isolates were cloned into a pET28a(+) plasmid vector. We also amplified and cloned genes encoding putative efflux pump proteins including: CzcABC family efflux RND transporter, Efflux ABC transporter (ATP-binding protein), MATE family of MDR efflux pump, small multidrug resistance family (SMR) protein and MFS-type transporter. These plasmids were transformed into BL21 (DE3) E. coli and the MICs of the common antibiotics were tested in the resultant strains. The strain transformed with pET-CME displayed an increased MIC of ampicillin, piperacillin, cefazolin, cefuroxime, ceftazidime, ceftriaxone and aztreonam compared with the pET28a(+) vector construct. This suggests that the extended-spectrum serine- $\beta$ - 
lactamase $\mathrm{CME}$ is functionally involved in cephalosporins and monobactams resistance (Table 5). The MIC of imipenem increased 32-fold (from 0.125 to $4 \mu \mathrm{g} / \mathrm{mL}$ ) in the presence of the pET-BlaB construct and 16-fold (from 0.125 to $2 \mu \mathrm{g} / \mathrm{mL}$ ) in the presence of the pET-GOB construct. This suggests that the MBLs BlaB and GOB are responsible for increased imipenem resistance (Table 5). Along with the increase in imipenem resistance, the pET-BlaB and pET-GOB constructs also conferred an increased MICs of ampicillin, piperacillin, cefazolin, cefuroxime and ceftazidime. This indicates that the MBLs BlaB and GOB also have the ability to degrade ampicillin, piperacillin, cefazolin, cefuroxime and ceftazidime (Table 5). All the efflux pump transformants tested, including pET-ABC, pET-MFS, pET-MATE, pET-SMR and pET-RND did not result in increased MICs of any antibiotics tested (Table 5).

\section{Discussion}

Infection with $E$. anophelis in humans is increasing in many countries [3-10]. Furthermore, there have been several reports of $E$. anophelis outbreaks in the community and nosocomial environment in Singapore and the Midwestern United States of Wisconsin, Illinois and Michigan [3, 5-8]. However, as previously mentioned, E. anophelis is commonly misidentified as $E$. meningoseptica by biochemical identification methods or automated identification systems in clinical settings. Therefore, data regarding the clinical features, clinical prognosis and the antimicrobial susceptibility profiles of $E$. anophelis could be skewed. For the first time this study identified the risk factors associated with the acquisition of $E$. anophelis. We show that anemia is an independent risk factor for in-hospital mortality in patients with E. anophelis infections. Moreover, we demonstrate for the first time that various putative efflux pumps in E. anophelis do not alter antimicrobial resistance, thus seemingly do not to possess a drug efflux function. $\beta$-lactamases were commonly found in E. anophelis isolates. The MBLs BlaB and GOB are responsible for carbapenem resistance, whereas the ESBL CME is functionally involved in resistance to cephalosporins and monobactams.

In the present study we initially explored risk factors leading to $E$. anophelis infection. Using multivariate analysis we found that coronary artery diseases, chronic obstructive pulmonary disease, surgery in the past 6 months, anemia and systemic steroid use were independently associated with $E$. anophelis infection. Previous studies have suggested that patients with $E$. anophelis infection could have more underlying comorbidities [3-10]. This study is the first to provide a statistical analysis to support this hypothesis. Moreover, surgery in the past 6 months, anemia and systemic steroid are known to compromise the immune status of the patients. Therefore, these patients are more vulnerable to acquiring E. anophelis infection in the same hospital environment.

In previous reports, the case fatality rate of patients with E. anophelis infection ranged from $24-60 \%$ in different countries [414]. In line with this, our study showed that the in-hospital mortality rate of patients with an E. anophelis infection was $51.3 \%$. We further explored the factors influencing mortality. Compared with the only previous study which investigated risk factors for mortality [10], our study demonstrated that anemia was the only independent predictor for mortality in patients infected with $E$. anophelis, a factor which has not been reported prior to the present study. Patients may present as anemic because of the hemolytic activity of $E$. anophelis. Several studies have reported that this bacterium lyse animal erythrocytes to access essential nutrients (such as amino acids) using hemolysins and heme-degrading proteins [20-22]. The process may alter the host physiological status and compromise the immune system, thus worsening the prognosis of patients infected with $E$. anophelis. Therefore, anemic patients with a confirmed $E$. anophelis infection should be considered as higher risk and should be given more attention and special care. Unexpectedly, inadequate antibiotic therapy was not associated with mortality probably because of the limited number of the infected patients in our study.

There is limited published information about the antimicrobial susceptibility patterns of $E$. anophelis identified using reliable methods. Studies from Singapore [15] and Taiwan $[14,16]$ demonstrated that $E$. anophelis were resistant to carbapenems, $\beta$ lactams, $\beta$-lactam/ $\beta$-lactam inhibitor and aminoglycosides. However, previous research showed that the susceptibility of $E$. anophelis to fluoroquinolones, tigecycline, piperacillin, piperacillin-tazobactam and trimethoprim-sulfamethoxazole was variable [4-6, 10, 17]. Using a disk diffusion or agar dilution test, studies from Hong Kong [4], South Korea [17] and the USA [5] reported the following susceptibilities of E. anophelis to ciprofloxacin (22-100\%), levofloxacin (29-96\%), piperacillin (41.1$100 \%)$, piperacillin-tazobactam (92\%), vancomycin (0-100\%) and trimethoprim-sulfamethoxazole (22-70.6\%). While when using the broth microdilution test, researchers from Taiwan $[14,16]$ and Singapore $[15]$ showed the following susceptibilities of 
E. anophelis to ciprofloxacin (1-21.5\%), levofloxacin (16-78.5\%), piperacillin (19.4\%), piperacillin-tazobactam (30.6-92.4\%), vancomycin (0\%), tigecycline (5.1-26.4\%), minocycline (97.5-100\%) and trimethoprim-sulfamethoxazole (4-92.4\%). As shown above, there are huge discrepancies in the susceptibility of $E$. anophelis to ciprofloxacin, levofloxacin, piperacillin and vancomycin between the disk diffusion or agar dilution test and the broth microdilution test. This suggests that the susceptibility of $E$. anophelis using the disk diffusion test or agar dilution test is unreliable and inaccurate as the broth microdilution test is the gold-standard method for antimicrobial susceptibility testing.

There are also obvious differences in the susceptibility of $E$. anophelis to antibacterial agents when the standard broth microdilution test is used. A possible explanation for this inconsistency is that natural geographical differences cause variation in the susceptibility patterns observed in previous studies. It is therefore necessary to investigate the antimicrobial susceptibility of $E$. anophelis in local area for to give effective guidance on antibiotic selection. To the best of our knowledge, this is the first study to investigate the antibiotic susceptibility of E. anophelis in China. Our study showed the following susceptibility of $E$. anophelis to minocycline (100\%), piperacillin-tazobactam (71.8\%), levofloxacin (38.5\%), ciprofloxacin (30.8\%), piperacillin (17.9\%), rifampicin (20.5\%) and tigecycline (10.3\%). All of the isolates displayed resistance to ceftazidime, cefepime, aztreonam, ceftazidime/clavulanic acid, cefepime/clavulanic acid, colistin and fosfomycin according to the breakpoints used. Most of the antimicrobial susceptibility results in this study are consistent with those of previous studies performed using the broth microdilution test. These results suggest that antimicrobial therapy for $E$. anophelis should prioritize minocycline or piperacillin-tazobactam. However, in this study, patients in the non-survival group were treated with significantly more $\beta$-lactam/lactamase inhibitor antibiotics as compared to the survival group $(P=0.041)$. This observation indicate that piperacillin-tazobactam is not an effective treatment for $E$. anophelis infections.

In this study, we screened for the presence of carbapenemase genes (blaKPC, blaIMP, blaVIM, blaNDM, blaBlaB, blaGOB and blaOXA-48-like) and ESBLs genes (blaTEM, blaSHV, blaCME and blaCTX-M) in all 39 E. anophelis isolates. No carbapenemase genes (blaKPC, blaIMP, blaVIM, blaNDM and blaOXA-48-like) or ESBLs genes (blaTEM, blaSHV and blaCTX-M) were detected in any isolates. However, we identified 35 (89.7\%) isolates co-harboring blaGOB, blaBlaB and blaCME $\beta$-lactamase genes. The most commonly detected combination of $\beta$-lactamases was CME-1, BlaB-29 and GOB-38 $(n=17)$.

To further evaluate the function of $\beta$-lactamases, recombinant strains harboring either blaCME, blaBlaB or blaGOB were constructed. The transformed strain expressing CME displayed an increased MIC of ampicillin, piperacillin, cefazolin, cefuroxime, ceftazidime, ceftriaxone and aztreonam as compared to the pET28a $(+)$ vector construct. This suggests that the ESBL CME is functionally involved in resistance to cephalosporins and monobactams. The MIC of imipenem increased $32-f o l d$ (from 0.125 to $4 \mu \mathrm{g} / \mathrm{mL}$ ) in the presence of the BlaB-expressing construct and 16-fold (from 0.125 to $2 \mu \mathrm{g} / \mathrm{mL}$ ) in the presence of the GOB-expressing construct. This suggests that the metallo- $\beta$-lactamases BlaB and GOB are responsible for the observed carbapenem resistance.

Aztreonam/avibactam is a novel class of combination $\beta$-lactamase-inhibitor designed to treat serious infections of metallo- $\beta$ lactamase (MBL)-producing, Gram-negative bacteria, which currently in phase I clinical trials (NCT01689207). Aztreonam is relatively stable against MBL hydrolysis, however, it is easily inactivated by class A (e.g., KPC), class C (e.g., AmpC) and certain class D (e.g., OXA-48) serine- $\beta$-lactamase enzymes [23]. Avibactam potently inhibits class $A$, class $C$ and certain class $D$ serine$\beta$-lactamase enzymes, which displays a broader $\beta$-lactamase inhibition profile than other $\beta$-lactamase inhibitors [23]. When combined, aztreonam/avibactam is effective against isolates co-producing ESBL and MBLs with porin loss/deficiency [24]. However, it is quite unexpected that $E$. anophelis is resistant to aztreonam/avibactam according to our experimental results.

Genomic annotation of all Elizabethkingia spp. reveals that besides $\beta$-lactamases, there are also numerous putative efflux pump proteins including: CzcABC family efflux RND transporter, Efflux ABC transporter (ATP-binding protein), MATE family of MDR efflux pump, small multidrug resistance family (SMR) protein and MFS-type transporter. Interestingly however, none of these transporters have been phenotypically characterized $[5,18,19,20]$. It was therefore critical to investigate the function of these putative efflux pumps. Our data show that all recombinant efflux pump strains including: pET-ABC, pET-MFS, pET-MATE, pET-SMR and pET-RND did not result in increased MICs for $\beta$-lactam and non- $\beta$-lactam antibiotics. These results suggest that the putative efflux pump genes from $E$. anophelis are not efflux pumps which mediate antimicrobial drug resistance. Similarly,

Page $7 / 16$ 
Schindler et al. cloned and expressed 21 putative efflux pump genes in Staphylococcus aureus which had no effect on any of the antibiotics tested [25]. In summary, we demonstrate for the first time that the various putative efflux pumps in E. anophelis do not to possess antimicrobial drug efflux function.

There were some limitations to our study. Firstly, the limited sample size from the single-center study limited its translation to the wider population. However, the identification of both a carbapenem resistance mechanism and the susceptibility profile of the extensively drug-resistant $E$. anophelis are of great clinical importance and warrant an urgent, wider, in-depth study. Secondly, no further investigation into the clonality of these isolates was performed, so the possibility of infection outbreaks cannot be ruled out.

\section{Conclusions}

Some conclusions of this study are significant. First, patients with anemia, coronary artery diseases, chronic obstructive pulmonary disease or patients who have received systemic steroids or surgery in the past 6 months are more likely to acquire an $E$. anophelis infection. A check list of the identified risk factors at hospital admission will help the clinicians identify high risk patients. Second, patients with anemia have a worse prognosis and therefore require more attention and special care from physicians. Third, our research reports the most prevalent rate of E. anophelis resistance to colistin (100\%), fosfomycin (100\%), aztreonam/avibactam (100\%) and tigecycline (89.7\%) which are regarded as last-resort treatments for carbapenem-resistant Enterobacteriaceae (CRE). Our results also showed that minocycline is the most effective antibiotic against $E$. anophelis. Fourth, mechanistic analysis reveals that carbapenem resistance is associated with the hydrolytic activity of the MBLs BlaB and $\mathrm{GOB}$, and is not associated with various putative efflux pumps expressed in E. anophelis.

\section{Abbreviations}

E. anophelis: Elizabethkingia anophelis; XDR: extensively drug-resistant; E. meningoseptica: Elizabethkingia meningoseptica; ORs: odds ratio; Cl: confidence interval; IQR: interquartile range; CLSI: clinical and Laboratory Standards Institute; MICs: minimum inhibitory concentrations; ESBL: extended-spectrum betalactamase; MBLs: metallo-betalactamases; WHO: World Health Organization; FDA: Food and Drug Administration; EUCAST: European Committee on Antimicrobial Susceptibility Testing; CDSs: coding sequences.

\section{Declarations}

\section{Ethics approval and consent to participate}

The Institutional Review Board and Ethics Committee of Chongqing Medical University approved this study. The collection of culture isolates and collation of anonymous clinical data was in accordance with the approved clinical practice guidelines. The need to give informed consent to the study was waived by the Institutional Review Board due to the nature of the retrospective analysis with no individual patient identifiers.

\section{Consent for publication}

Not applicable

\section{Availability of data and materials}

Not applicable

\section{Competing interests}


The authors declare that they have no competing interests.

\section{Funding}

This study was supported by the Natural Science Foundation of Chongqing (No.cstc2019jcyj-msxmX0253). The funders had no role in study design, data collection and analysis, decision to publish or preparation of the manuscript.

\section{Authors' contributions}

YC, SN, and XZ designed the study. YC, DZ, QC, and QL performed the experiments. YC and DZ analyzed the data. YC and XZ wrote this manuscript. All authors read and approved the final manuscript.

\section{Acknowledgements}

Not applicable

\section{References}

1. Kampfer P, Matthews H, Glaeser SP, Martin K, Lodders N, Faye I. Elizabethkingia anophelis sp. nov., isolated from the midgut of the mosquito Anopheles gambiae. Int J Syst Evol Microbiol. 2011;61(Pt 11):2670-5.

2. Frank T, Gody JC, Nguyen LB, Berthet N, Le Fleche-Mateos A, Bata P, et al. First case of Elizabethkingia anophelis meningitis in the Central African Republic. Lancet. 2013;381(9880):1876.

3. Teo J, Tan SY, Tay M, Ding Y, Kjelleberg S, Givskov M, et al. First case of E anophelis outbreak in an intensive-care unit. Lancet. 2013;382(9895):855-6.

4. Lau SK, Chow WN, Foo CH, Curreem SO, Lo GC, Teng JL, et al. Elizabethkingia anophelis bacteremia is associated with clinically significant infections and high mortality. Sci Rep. 2016;6:26045.

5. Perrin A, Larsonneur E, Nicholson AC, Edwards DJ, Gundlach KM, Whitney AM, et al. Evolutionary dynamics and genomic features of the Elizabethkingia anophelis 2015 to 2016 Wisconsin outbreak strain. Nat Commun. 2017;8:15483.

6. Navon L, Clegg WJ, Morgan J, Austin C, McQuiston JR, Blaney DD, et al. Notes from the Field: Investigation of Elizabethkingia anophelis Cluster - Illinois, 2014-2016. MMWR Morb Mortal Wkly Rep. 2016;65(48):1380-1.

7. WISCONSIN DEPARTMENT of HEALTH SERVICES: Elizabethkingia. https://www.dhs.wisconsin.gov/disease/elizabethkingia.htm. Accessed 17 April 2017.

8. CDC. Elizabethkingia, Recent Outbreaks. https://www.cdc.gov/elizabethkingia/outbreaks/. Accessed 26 December 2016.

9. Choi MH, Kim M, Jeong SJ, Choi JY, Lee IY, Yong TS, et al. Risk Factors for Elizabethkingia Acquisition and Clinical Characteristics of Patients, South Korea. Emerg Infect Dis. 2019;25(1):42-51.

10. Lin JN, Lai CH, Yang CH, Huang YH, Lin HH. Clinical manifestations, molecular characteristics, antimicrobial susceptibility patterns and contributions of target gene mutation to fluoroquinolone resistance in Elizabethkingia anophelis. J Antimicrob Chemother. 2018;73(9):2497-502.

11. Janda JM, Lopez DL. Mini review: New pathogen profiles: Elizabethkingia anophelis. Diagn Microbiol Infect Dis. 2017;88(2):201-5.

12. Lin JN, Lai CH, Yang CH, Huang YH. Elizabethkingia Infections in Humans: From Genomics to Clinics. Microorganisms. 2019;7(9).

13. Lin JN, Lai CH, Yang CH, Huang YH, Lin HF, Lin HH. Comparison of four automated microbiology systems with 16S rRNA gene sequencing for identification of Chryseobacterium and Elizabethkingia species. Sci Rep. 2017;7(1):13824. 
14. Lin JN, Lai CH, Yang CH, Huang YH. Comparison of Clinical Manifestations, Antimicrobial Susceptibility Patterns, and Mutations of Fluoroquinolone Target Genes between Elizabethkingia meningoseptica and Elizabethkingia anophelis Isolated in Taiwan. J Clin Med. 2018;7(12).

15. Chew KL, Cheng B, Lin RTP, Teo JWP. Elizabethkingia anophelis Is the Dominant Elizabethkingia Species Found in Blood Cultures in Singapore. J Clin Microbiol. 2018;56(3).

16. Cheng YH, Perng CL, Jian MJ, Cheng YH, Lee SY, Sun JR, et al. Multicentre study evaluating matrix-assisted laser desorption ionization-time of flight mass spectrometry for identification of clinically isolated Elizabethkingia species and analysis of antimicrobial susceptibility. Clin Microbiol Infect. 2019;25(3):340-5.

17. Han MS, Kim H, Lee Y, Kim M, Ku NS, Choi JY, et al. Relative Prevalence and Antimicrobial Susceptibility of Clinical Isolates of Elizabethkingia Species Based on 16S rRNA Gene Sequencing. J Clin Microbiol. 2017;55(1):274-80.

18. Lin JN, Lai CH, Yang CH, Huang YH, Lin HH. Genomic features, phylogenetic relationships, and comparative genomics of Elizabethkingia anophelis strain EM361-97 isolated in Taiwan. Sci Rep. 2017;7(1):14317.

19. Breurec S, Criscuolo A, Diancourt L, Rendueles $O$, Vandenbogaert M, Passet V, et al. Genomic epidemiology and global diversity of the emerging bacterial pathogen Elizabethkingia anophelis. Sci Rep. 2016;6:30379.

20. Li Y, Liu Y, Chew SC, Tay M, Salido MM, Teo J, et al. Complete Genome Sequence and Transcriptomic Analysis of the Novel Pathogen Elizabethkingia anophelis in Response to Oxidative Stress. Genome Biol Evol. 2015;7(6):1676-85.

21. Chen S, Bagdasarian M, Walker ED. Elizabethkingia anophelis: molecular manipulation and interactions with mosquito hosts. Appl Environ Microbiol. 2015;81(6):2233-43.

22. Kukutla P, Lindberg BG, Pei D, Rayl M, Yu W, Steritz M, et al. Insights from the genome annotation of Elizabethkingia anophelis from the malaria vector Anopheles gambiae. PLoS One. 2014;9(5):e97715.

23. Wong D, van Duin D. Novel Beta-Lactamase Inhibitors: Unlocking Their Potential in Therapy. Drugs. 2017;77(6):615-28.

24. Zou H, Xiong SJ, Lin QX, Wu ML, Niu SQ, Huang SF. CP-CRE/non-CP-CRE Stratification And CRE Resistance Mechanism Determination Help In Better Managing CRE Bacteremia Using Ceftazidime-Avibactam And Aztreonam-Avibactam. Infect Drug Resist. 2019;12:3017-27.

25. Schindler BD, Frempong-Manso E, DeMarco CE, Kosmidis C, Matta V, Seo SM, et al. Analyses of multidrug efflux pump-like proteins encoded on the Staphylococcus aureus chromosome. Antimicrob Agents Chemother. 2015;59(1):747-8.

\section{Tables}

\section{Table 1 Univariate and multivariate analysis of clinical features of patients infected with $E$. anophelis isolates.}




\begin{tabular}{|c|c|c|c|c|c|c|}
\hline Variable & E. anophelis & Controls & Univariable & & Multivariable & \\
\hline & $\mathrm{n}=39(\%)$ & $\begin{array}{l}n=117 \\
(\%)\end{array}$ & $95 \% \mathrm{Cl}$ & $\begin{array}{l}P \\
\text { Value }\end{array}$ & $95 \% \mathrm{Cl}$ & $\begin{array}{l}P \\
\text { Value }\end{array}$ \\
\hline Gender (male) & $21(53.8)$ & $73(62.4)$ & $0.70(0.34-1.46)$ & 0.352 & & \\
\hline Age, median, y (IQR) & $66(52-76)$ & $\begin{array}{l}54(41- \\
67)\end{array}$ & - & 0.003 & & \\
\hline Elderly ( $\geq 60$ y) & $26(66.7)$ & $58(49.6)$ & $2.03(0.95-4.34)$ & 0.067 & & \\
\hline ICU admission & $18(46.2)$ & $47(40.2)$ & $1.28(0.62-2.65)$ & 0.575 & & \\
\hline \multicolumn{7}{|l|}{$\begin{array}{l}\text { Underlying diseases and } \\
\text { conditions }\end{array}$} \\
\hline Diabetes & $9(23.1)$ & $20(17.1)$ & $1.46(0.60-3.53)$ & 0.476 & & \\
\hline Hypertension & $18(46.2)$ & $31(26.5)$ & $2.38(1.12-5.04)$ & 0.029 & & \\
\hline Shock & $8(20.5)$ & $17(14.5)$ & $1.52(0.60-3.86)$ & 0.450 & & \\
\hline Solid malignancy & $9(23.7)$ & $32(27.4)$ & $0.82(0.35-1.93)$ & 0.833 & & \\
\hline Hematologic malignancy & $6(15.4)$ & $12(10.3)$ & $1.59(0.55-4.57)$ & 0.393 & & \\
\hline Peripheral vascular diseases & $1(2.6)$ & $16(13.7)$ & $0.17(0.02-1.30)$ & 0.073 & & \\
\hline Coronary artery diseases & $13(33.3)$ & $22(18.8)$ & $2.16(0.96-4.86)$ & 0.076 & $\begin{array}{l}5.81(1.09- \\
30.93)\end{array}$ & 0.039 \\
\hline Cerebrovascular diseases & $15(38.5)$ & $20(17.1)$ & $3.03(1.36-6.78)$ & 0.008 & & \\
\hline $\begin{array}{l}\text { Chronic obstructive pulmonary } \\
\text { diseases }\end{array}$ & $\begin{array}{l}30 \\
(76.9)\end{array}$ & $28(23.9)$ & $\begin{array}{l}10.60(4.50- \\
24.98)\end{array}$ & 0.000 & $\begin{array}{l}6.71(1.55- \\
28.99)\end{array}$ & 0.011 \\
\hline Gastrointestinal diseases & $14(35.9)$ & $26(22.2)$ & $1.96(0.89-4.30)$ & 0.096 & & \\
\hline Hepatobiliary diseases & $13(33.3)$ & $21(17.9)$ & $2.29(1.01-5.17)$ & 0.071 & & \\
\hline Renal diseases & $16(41.0)$ & $26(22.2)$ & $2.44(1.12-5.27)$ & 0.036 & & \\
\hline Immune system diseases & $0(0.0)$ & $14(12.0)$ & $0.73(0.66-0.80)$ & 0.022 & & \\
\hline \multicolumn{7}{|l|}{ Invasive procedures } \\
\hline Mechanical ventilation & $9(23.1)$ & $35(29.9)$ & $0.70(0.30-1.63)$ & 0.538 & & \\
\hline Central venous catheterization & $14(35.9)$ & $27(23.1)$ & $1.87(0.85-4.08)$ & 0.142 & & \\
\hline Drainage tube & $11(28.2)$ & $35(29.9)$ & $0.92(0.41-2.05)$ & 1.000 & & \\
\hline Nasogastric tube insertion & $17(43.6)$ & $48(41.0)$ & $1.11(0.53-2.31)$ & 0.852 & & \\
\hline Urinary catheter & $16(41.0)$ & $59(50.4)$ & $0.68(0.33-1.42)$ & 0.357 & & \\
\hline Surgery in the past 6 months & $27(69.2)$ & $31(26.5)$ & $\begin{array}{l}6.24(2.82- \\
13.81)\end{array}$ & 0.000 & $\begin{array}{l}18.04(3.29- \\
98.87)\end{array}$ & 0.001 \\
\hline \multicolumn{7}{|l|}{ Immunosuppressive state } \\
\hline Anemia & $26(66.7)$ & $14(12.0)$ & $\begin{array}{l}14.71(6.17- \\
35.08)\end{array}$ & 0.000 & $\begin{array}{l}6.72(1.12- \\
40.42)\end{array}$ & 0.038 \\
\hline Hypoproteinemia & $36(92.3)$ & $60(51.3)$ & $\begin{array}{l}11.40(3.32- \\
39.09)\end{array}$ & 0.000 & & \\
\hline Hypokalemia & $14(35.9)$ & $14(12.0)$ & $4.12(1.74-9.74)$ & 0.002 & & \\
\hline
\end{tabular}


Notes: ICU, intensive care unit; Bold face indicate values that are significant $(P<0.05)$.

\section{Table 2 Risk factors associated with in-hospital mortality.}

\begin{tabular}{|c|c|c|c|c|c|c|}
\hline Variable & $\begin{array}{l}\text { Non- } \\
\text { survival }\end{array}$ & Survival & Univariable & & Multivariable & \\
\hline & $\mathrm{n}=20(\%)$ & $\begin{array}{l}n=19 \\
(\%)\end{array}$ & $95 \% \mathrm{Cl}$ & $\begin{array}{l}P \\
\text { Value }\end{array}$ & $95 \% \mathrm{Cl}$ & $\begin{array}{l}P \\
\text { Value }\end{array}$ \\
\hline Gender (female) & $8(40.0)$ & $\begin{array}{l}13 \\
(68.4)\end{array}$ & $0.31(0.08-1.15)$ & 0.080 & & \\
\hline Elderly ( $\geq 60$ y) & $16(80.0)$ & $\begin{array}{l}10 \\
(52.6)\end{array}$ & $3.60(0.87-14.87)$ & 0.077 & & \\
\hline Drinking history & $2(10.0)$ & $7(36.8)$ & $0.19(0.04-1.08)$ & 0.061 & & \\
\hline ICU admission & $12(60.0)$ & $6(31.6)$ & $3.25(0.87-12.14)$ & 0.080 & & \\
\hline Cerebrovascular disease & $11(55.0)$ & $4(21.1)$ & $4.58(1.12-18.80)$ & 0.035 & & \\
\hline Central nervous system disease & $13(65.0)$ & $7(36.8)$ & $3.18(0.86-11.79)$ & 0.083 & & \\
\hline $\begin{array}{l}\text { Chronic obstructive pulmonary } \\
\text { disease }\end{array}$ & $\begin{array}{l}19 \\
(95.0)\end{array}$ & $\begin{array}{l}11 \\
(57.9)\end{array}$ & $\begin{array}{l}13.82(1.52- \\
125.65)\end{array}$ & 0.020 & & \\
\hline Central venous catheterization & $10(50.0)$ & $4(21.1)$ & $3.75(0.92-15.34)$ & 0.066 & & \\
\hline Nasogastric tube insertion & $13(65.0)$ & $4(21.1)$ & $6.96(1.66-29.26)$ & 0.008 & & \\
\hline Anemia & $19(95.0)$ & $7(36.8)$ & $\begin{array}{l}32.57(3.55- \\
298.83)\end{array}$ & 0.002 & $\begin{array}{l}86.38(1.42- \\
5251.29)\end{array}$ & 0.033 \\
\hline Systemic steroid use & $5(25.0)$ & $2(10.5)$ & $2.83(0.48-16.81)$ & 0.252 & & \\
\hline
\end{tabular}

Notes: ICU, intensive care unit; Bold face indicate values that are significant $(P<0.05)$.

\section{Table 3 Antimicrobial susceptibilities of $E$. anophelis isolates determined by the broth microdilution method.}




\begin{tabular}{|c|c|c|c|c|c|c|c|c|}
\hline \multirow{2}{*}{$\begin{array}{l}\text { Antimicrobial } \\
\text { agents }\end{array}$} & \multicolumn{2}{|l|}{$\begin{array}{l}\text { Breakpoint } \\
(\mu \mathrm{g} / \mathrm{ml})\end{array}$} & \multicolumn{3}{|c|}{ MIC $(\mu \mathrm{g} / \mathrm{ml})$} & \multicolumn{3}{|l|}{ Susceptibility (\%) } \\
\hline & Susceptible & Resistant & Range & $50 \%$ & $90 \%$ & Susceptible & Intermediate & Resistant \\
\hline Minocycline & $\leq 4$ & $\geq 16$ & $0.25-1$ & 0.5 & 1 & 100 & 0 & 0 \\
\hline $\begin{array}{l}\text { Piperacillin- } \\
\text { TZB }\end{array}$ & $\leq 16$ & $\geq 128$ & $4-64$ & 16 & 32 & 71.8 & 28.2 & 0 \\
\hline Levofloxacin & $\leq 2$ & $\geq 8$ & $0.5-32$ & 8 & 16 & 38.5 & 2.6 & 60.0 \\
\hline Ciprofloxacin & $\leq 1$ & $\geq 4$ & $\begin{array}{l}0.5 \text { to } \\
>256\end{array}$ & 64 & 256 & 30.8 & 2.6 & 66.6 \\
\hline Rifampicin & $\leq 1$ & $\geq 4$ & $1-32$ & 2 & 16 & 20.5 & 33.3 & 46.2 \\
\hline Tigecycline & $\leq 2$ & $\geq 8$ & $2-8$ & 4 & 4 & 10.3 & 82.1 & 7.6 \\
\hline Piperacillin & $\leq 16$ & $\geq 128$ & $\begin{array}{l}16- \\
128\end{array}$ & 32 & 64 & 17.9 & 74.4 & 7.7 \\
\hline Vancomycin & $\leq 2$ & $\geq 16$ & $8-32$ & 16 & 32 & 0 & 20.5 & 79.5 \\
\hline Ceftazidime & $\leq 8$ & $\geq 32$ & $\begin{array}{l}128 \text { to } \\
>256\end{array}$ & $>256$ & $>256$ & 0 & 0 & 100 \\
\hline $\begin{array}{l}\text { Ceftazidime- } \\
\text { AVI }\end{array}$ & $\leq 8$ & $\geq 16$ & $\begin{array}{l}64 \text { to } \\
>256\end{array}$ & $>256$ & $>256$ & 0 & 0 & 100 \\
\hline $\begin{array}{l}\text { Ceftazidime- } \\
\text { CLA }\end{array}$ & $\leq 8$ & $\geq 32$ & $\begin{array}{l}32 \text { to } \\
>256\end{array}$ & $>256$ & $>256$ & 0 & 0 & 100 \\
\hline Aztreonam & $\leq 8$ & $\geq 32$ & $>256$ & $>256$ & $>256$ & 0 & 0 & 100 \\
\hline $\begin{array}{l}\text { Aztreonam- } \\
\text { AVI }\end{array}$ & $\leq 8$ & $\geq 16$ & $>256$ & $>256$ & $>256$ & 0 & 0 & 100 \\
\hline Cefepime & $\leq 8$ & $\geq 32$ & $\begin{array}{l}32 \text { to } \\
>256\end{array}$ & $>256$ & $>256$ & 0 & 0 & 100 \\
\hline $\begin{array}{l}\text { Cefepime- } \\
\text { CLA }\end{array}$ & $\leq 8$ & $\geq 32$ & $\begin{array}{l}32 \text { to } \\
>256\end{array}$ & 256 & $>256$ & 0 & 0 & 100 \\
\hline Fosfomycin & $\leq 32$ & $>32$ & $>256$ & $>256$ & $>256$ & 0 & 0 & 100 \\
\hline Colistin & $\leq 2$ & $>2$ & $>256$ & $>256$ & $>256$ & 0 & 0 & 100 \\
\hline
\end{tabular}

Notes: TZB, tazobactam at a fixed concentration of $4 \mu \mathrm{g} / \mathrm{ml} ; \mathrm{AVl}$, avibactam at a fixed concentration of $4 \mu \mathrm{g} / \mathrm{ml} ; \mathrm{CLA}$, clavulanic acid at a fixed concentration of $2 \mu \mathrm{g} / \mathrm{ml}$.

\section{Table 4 Empirical antimicrobial therapy in patients infected with $E$. anophelis isolates.}




\begin{tabular}{|c|c|c|c|c|}
\hline $\begin{array}{l}\text { Isolates } \\
\text { No. }\end{array}$ & Specimen & ESBL+MBLs & Empirical antimicrobial therapy & Prognosis \\
\hline N01 & Blood & CME-1+ BlaB-2+ GOB-20 & Ceftazidime+ Levofloxacin+ Teicoplanin & Survival \\
\hline NO2 & Sputum & CME-1+ BlaB-2+ GOB-20 & Cefoperazone-sulbactam+ Minocycline & $\begin{array}{l}\text { Non- } \\
\text { survival }\end{array}$ \\
\hline NO3 & Sputum & CME-1+ BlaB-29+ GOB-38 & Cefoperazone-sulbactam+ Teicoplanin & $\begin{array}{l}\text { Non- } \\
\text { survival }\end{array}$ \\
\hline NO4 & Urine & CME-1+ BlaB-29+ GOB-38 & & Survival \\
\hline N05 & Sputum & CME-1+ BlaB-29+ GOB-38 & $\begin{array}{l}\text { Cefoperazone-sulbactam+ Minocycline+ } \\
\text { Levofloxacin+ Teicoplanin }\end{array}$ & $\begin{array}{l}\text { Non- } \\
\text { survival }\end{array}$ \\
\hline N06 & Sputum & CME-1+ BlaB-34+ GOB-32 & Piperacillin-tazobactam+ Imipenem & $\begin{array}{l}\text { Non- } \\
\text { survival }\end{array}$ \\
\hline NO7 & Urine & CME-1+ BlaB-29+ GOB-38 & Meropenem & Survival \\
\hline N08 & Urine & CME-1+ BlaB-29+ GOB-38 & Imipenem+ Cefoperazone-sulbactam & $\begin{array}{l}\text { Non- } \\
\text { survival }\end{array}$ \\
\hline N09 & Sputum & CME-1+ BlaB-29+ GOB-38 & Imipenem+ Clindamycin+ Teicoplanin+ Cefepime & Survival \\
\hline N010 & Blood & CME-1+ BlaB-29+ GOB-38 & Imipenem+ Gentamicin+ Teicoplanin & $\begin{array}{l}\text { Non- } \\
\text { survival }\end{array}$ \\
\hline N011 & Sputum & CME-1+ BlaB-33+ GOB-4 & Cefazolin & $\begin{array}{l}\text { Non- } \\
\text { survival }\end{array}$ \\
\hline N012 & Urine & CME-1+ BlaB-2+ GOB-50 & Teicoplanin & $\begin{array}{l}\text { Non- } \\
\text { survival }\end{array}$ \\
\hline N013 & Sputum & CME-1+ BlaB-29+ GOB-38 & Piperacillin-tazobactam+ ceftriaxone+ Ornidazole & Survival \\
\hline N014 & $\begin{array}{l}\text { Cerebrospinal } \\
\text { fluid }\end{array}$ & & Levofloxacin & Survival \\
\hline N015 & Blood & CME-1+ BlaB-3+ GOB-45 & Teicoplanin & Survival \\
\hline N016 & Sputum & CME-1+ BlaB-9+ GOB-32 & Levofloxacin+ Cefazolin+ Amikacin & $\begin{array}{l}\text { Non- } \\
\text { survival }\end{array}$ \\
\hline N017 & Sputum & CME-1+ BlaB-1+ GOB-32 & Imipenem+ Teicoplanin & $\begin{array}{l}\text { Non- } \\
\text { survival }\end{array}$ \\
\hline N018 & Amniotic fluid & $\mathrm{CME}-1+\mathrm{BlaB}-1+\mathrm{GOB}-38$ & Cefuroxime & Survival \\
\hline N019 & Blood & & Ceftriaxone + Vancomycin & Survival \\
\hline NO20 & Sputum & CME-1+ BlaB-2+ GOB-20 & Cefazolin & $\begin{array}{l}\text { Non- } \\
\text { survival }\end{array}$ \\
\hline NO21 & Sputum & CME-1+ BlaB-2+ GOB-50 & $\begin{array}{l}\text { Cefoperazone-sulbactam+ Levofloxacin+ } \\
\text { Imipenem+ Teicoplanin }\end{array}$ & Survival \\
\hline NO22 & Sputum & CME-1+ BlaB-17+ GOB-40 & Amikacin & Survival \\
\hline NO23 & $\begin{array}{l}\text { Cerebrospinal } \\
\text { fluid }\end{array}$ & CME-1+ BlaB-17+ GOB-20 & Levofloxacin & Survival \\
\hline NO24 & $\begin{array}{l}\text { Conjunctival } \\
\text { sac }\end{array}$ & CME-1+ BlaB-29+ GOB-38 & Cefazolin & Survival \\
\hline NO25 & Sputum & CME-2+ BlaB-2+ GOB-39 & Imipenem+ Teicoplanin+ Ornidazole & Survival \\
\hline NO26 & $\begin{array}{l}\text { Peritoneal } \\
\text { fluid }\end{array}$ & CME-1+ BlaB-29+ GOB-38 & Meropenem+ Vancomycin & $\begin{array}{l}\text { Non- } \\
\text { survival }\end{array}$ \\
\hline
\end{tabular}




\begin{tabular}{|c|c|c|c|c|}
\hline N027 & Urine & CME-1+ BlaB-29+ GOB-38 & $\begin{array}{l}\text { Meropenem+ Vancomycin+ Amikacin+ } \\
\text { ceftazidime }\end{array}$ & $\begin{array}{l}\text { Non- } \\
\text { survival }\end{array}$ \\
\hline NO28 & $\begin{array}{l}\text { Cerebrospinal } \\
\text { fluid }\end{array}$ & CME-1+ BlaB-29+ GOB-38 & Ceftriaxone & $\begin{array}{l}\text { Non- } \\
\text { survival }\end{array}$ \\
\hline NO29 & Sputum & CME-1+ BlaB-29+ GOB-38 & Linezolid+ Imipenem & Survival \\
\hline N030 & Corneal & CME-1+ BlaB-29+ GOB-38 & Amikacin & Survival \\
\hline N031 & Blood & $\begin{array}{l}\text { CME-1+ BlaB-29+ } \\
\text { GOB-38 }\end{array}$ & Imipenem + Levofloxacin+ Amikacin+ Teicoplanin & $\begin{array}{l}\text { Non- } \\
\text { survival }\end{array}$ \\
\hline N032 & Sputum & BlaB-1+ GOB-20 & Cefoperazone-sulbactam+ Minocycline & $\begin{array}{l}\text { Non- } \\
\text { survival }\end{array}$ \\
\hline NO33 & Urine & $\mathrm{CME}-1+\mathrm{BlaB}-1+\mathrm{GOB}-20$ & Cefepime+ Cefoperazone-sulbactam & $\begin{array}{l}\text { Non- } \\
\text { survival }\end{array}$ \\
\hline N034 & Sputum & CME-1+ GOB-38 & Imipenem & Survival \\
\hline N035 & Sputum & CME-1+ BlaB-29+ GOB-38 & Cefoperazone-sulbactam+ Minocycline & Survival \\
\hline N036 & Urine & $\begin{array}{l}\text { CME-1+ BlaB-17+ } \\
\text { GOB-50 }\end{array}$ & $\begin{array}{l}\text { efoperazone-sulbactam+ Amikacin+ } \\
\text { etronidazole+ Ceftriaxone }\end{array}$ & $\begin{array}{l}\text { Non- } \\
\text { survival }\end{array}$ \\
\hline N037 & Blood & CME-2+ BlaB-1+ GOB-20 & $\begin{array}{l}\text { Meropenem+ Cefoperazone-sulbactam+ } \\
\text { Piperacillin-tazobactam }\end{array}$ & $\begin{array}{l}\text { Non- } \\
\text { survival }\end{array}$ \\
\hline N038 & Sputum & $\begin{array}{l}\text { CME-1+ BlaB-1+ } \\
\text { GOB-20 }\end{array}$ & nem+ Teicoplanin+ Piperacillin-tazobactam & $\begin{array}{l}\text { Non- } \\
\text { survival }\end{array}$ \\
\hline N039 & Urine & CME-1+ BlaB-29+ GOB-38 & & Survival \\
\hline
\end{tabular}

\section{Table 5 The antibiotic susceptibilities of BL21(DE3) E. coli expressing CME, BlaB, $\mathrm{GOB}$, putative efflux proteins or the pET28a(+) vector.}




\begin{tabular}{|c|c|c|c|c|c|c|c|c|c|c|c|c|}
\hline \multirow{2}{*}{$\begin{array}{l}\text { BL21 with } \\
\text { recombinant } \\
\text { plasmid }\end{array}$} & \multicolumn{12}{|c|}{$\mathrm{MIC}(\mu \mathrm{g} / \mathrm{ml})$} \\
\hline & AMP & PIP & CFZ & CXM & CAZ & CRO & FEP & AZT & IPM & AK & CIP & TGC \\
\hline $\begin{array}{l}\text { pET28a(+) } \\
\text { vector }\end{array}$ & 0.5 & 0.5 & 1 & 1 & 1 & $<0.125$ & $<0.125$ & $<0.125$ & 0.125 & 8 & $<0.125$ & 4 \\
\hline pET-CME & 32 & 4 & 32 & 32 & 64 & 1 & $<0.125$ & 8 & 0.25 & 8 & $<0.125$ & 4 \\
\hline pET-BlaB & 256 & 128 & 2 & 16 & 4 & $<0.125$ & $<0.125$ & $<0.125$ & 4 & 4 & $<0.125$ & 4 \\
\hline pET-GOB & 4 & 2 & 4 & 8 & 16 & $<0.125$ & $<0.125$ & $<0.125$ & 2 & 4 & $<0.125$ & 4 \\
\hline pET-ABC & 0.5 & 1 & 1 & 1 & 1 & $<0.125$ & $<0.125$ & $<0.125$ & 0.25 & 8 & $<0.125$ & 4 \\
\hline pET-MFS & 1 & 0.5 & 2 & 1 & 1 & $<0.125$ & $<0.125$ & $<0.125$ & 0.25 & 8 & $<0.125$ & 4 \\
\hline pET-MATE & 0.5 & 0.5 & 2 & 1 & 1 & $<0.125$ & $<0.125$ & $<0.125$ & 0.25 & 8 & $<0.125$ & 4 \\
\hline pET-SMR & 1 & 0.5 & 2 & 1 & 1 & $<0.125$ & $<0.125$ & $<0.125$ & 0.25 & 8 & $<0.125$ & 4 \\
\hline pET-RND & 0.5 & 0.5 & 2 & 1 & 1 & $<0.125$ & $<0.125$ & $<0.125$ & 0.25 & 8 & $<0.125$ & 4 \\
\hline
\end{tabular}

Notes: Bold face indicate MIC values that increase at least 4-fold as compared to the pET28a(+) vector.

Abbreviations: AMP, ampicillin; PIP, piperacillin; CFZ, cefazolin; CXM, cefuroxime; CAZ, ceftazidime; CRO, ceftriaxone; FEP, cefepime; AZT, aztreonam; IPM, imipenem; AK, amikacin; CIP, ciprofloxacin; TGC, tigecycline; CME, extended-spectrum serinebetalactamase $\mathrm{CME}$ (class A); BlaB, metallo-betalactamase BlaB (subclass B1); GOB, metallo-betalactamase GOB (subclass $B 3) ; A B C$, efflux ABC transporter (ATP-binding protein); MFS, MFS-type transporter; MATE, MATE family of MDR efflux pump; SMR, small multidrug resistance family (SMR) protein; RND, CzcABC family efflux RND transporter.

\section{Supplementary Files}

This is a list of supplementary files associated with this preprint. Click to download.

- Additionalfile1Primersusedinthisstudy.docx 